\title{
ANÁLISE GEOMORFOLÓGICA DA REGIÃO ENTRE OS MUNICÍPIOS DE ITACOATIARA, SILVES E ITAPIRANGA, NORDESTE DO ESTADO DO AMAZONAS
}

\section{GEOMORPHOLOGICAL ANALYSIS OF THE REGION BETWEEN THE CITIES OF ITACOATIARA, SILVES AND ITAPIRANGA, NORTHEASTERN STATE OF AMAZON}

\author{
Maria Mirtes Cortinhas dos Santos \\ Departamento de Geociencias, Universidade Federal do Amazonas \\ Campus Universitário Senador Arthur Virgílio Filho, Manaus, Amazonas, CEP: 69077-000, Brasil
}

Email:mmcortinhas@gmail.com

Valmir da Silva Souza

Instituto de Geociências, Universidade de Brasília

Campus Universitário Darcy Ribeiro, Brasilia, Distrito Federal, CEP: 70.710-900, Brasil

Email:valmirsouzaunb@gmail.com

\section{Informações sobre o Artigo}

Data de Recebimento:

22/05/2015

Data de Aprovação:

$16 / 07 / 2015$

\section{Palavras-chave:}

Morfoesculturas, Controle

Estrutural, Neotectônica.

\section{Keywords:}

Morphosculptures, Structural

Control, Neotectonic.

\section{Resumo:}

O principal objetivo desse estudo foi caracterizar as feições morfoesculturais e morfoestruturais correlacionando-as com as unidades geológicas, ao longo das rodovias estaduais AM-010 e AM-363, abrangendo os municípios de Itacoatiara, Silves e Itapiranga, os quais estão inseridos nas unidades morfoestruturais do Planalto Dissecado Rio Trombetas - Rio Negro e Planície Amazônica. As feições geomorfológicas estão esculpidas sobre rochas pertencentes as Formação Alter do Chão e Novo Remanso. O Planalto Dissecado Rio Trombetas-Rio Negro comparece sob formas de platôs e colinas. As colinas apresentam topos convexos (Dc) com amplitude de até $1 \mathrm{~km}$ de extensão por $200 \mathrm{~m}$ de largura e altimetria, atingindo $80 \mathrm{~m}$. Por outro lado, os platôs apresentam topos aplainados e conservados (Dptac), topos convexos (Dptc) e topos aplainados (Dpta), com amplitudes que variam entre 1 a $8 \mathrm{~km}$ de extensão com 100 a 400 metros de largura e altimetria de até $150 \mathrm{~m}$. Na área restrita a Planície Amazônica, às formas de relevo mais representativas são os terraços fluviais, os paranás, as ilhas, os lagos e os "furos" que se encontram principalmente sob a ação hidrodinâmica do rio Amazonas. A análise geométrica dos elementos estruturais fotointerpretados, combinados com observações de campo, resultou na identificação de falhas normais em arranjo lístrico e permitiu elaborar um modelo morfoestrutural representado por um sistema de prismas escalonados, os quais mergulham cerca de $25^{\circ}$ para SW. 


\begin{abstract}
:
The main objective of this study was to characterize the morphosculpture, morphostructural features correlating with geological units along the highways AM- 010 and AM -363, covering the municipalities of Itacoatiara, Silves and Itapiranga which are inserted in morphostructural units of Rio Trombetas - Rio Negro Dissected Plateau and Amazon Plain,in the State of Amazonas. The geomorphological features are carved on rocks belonging to the Alter do Chão e Novo Remanso Formations. The Trombetas - Negro rivers Dissected Plateau appears in forms of plateaus and hills. The hills have convex tops (Dc) with amplitude of up to $1 \mathrm{~km}$ long by $200 \mathrm{~m}$ wide and altimetry reaching $80 \mathrm{~m}$. On the other hand, the plateaus have flat tops preserved (Dptac), convex tops (Dptc) and flat tops (Dtpa), with amplitudes ranging between 1-8 km long with 100 to 400 meters wide and up to $150 \mathrm{~m}$ altimetry . In the restricted area of Amazon Plain, the most representative forms of relief are the river terraces, the riverbanks, islands and lakes which are mainly under hydrodynamic action of the Amazon River. The geometric analysis of photointerpreted structural elements combined with field observations resulted in the identification of an arrangement normal listric faults allowed develop a morphostructural model represented by a system of staggered prisms which dip about $25^{\circ}$ to south-west.
\end{abstract}

\section{Introdução}

A área de estudo encontra-se na porção nordeste do Estado do Amazonas e compreende os municípios de Itacoatiara, Silves e Itapiranga. Essa área está inserida no contexto das morfoestruturas, denominadas de Planalto Dissecado Rio Trombetas-Rio Negro e Planície Amazônica (RADAMBRASIL, 1976) e é recoberta por uma floresta densa, com clima tropical chuvoso úmido (Figura 1).

Esse trabalho caracteriza as feições geomorfológicas e morfoestruturais associadas as formações, Alter do Chão e Novo Remanso. A caracterização das feições geomorfológicas nessa região tem sido tratada desde a década de 50 nos trabalhos de Sternberg(1950), quando percebeu alinhamentos e paralelismos dos rios Urubu e Rio Preto da Eva.

A partir da década de 80, Franzinelli e Piuci (1988), Iriondo e Suguio (1981), Costa (1996), Costa et al. (1996), Costa et al (2001), Igreja e Catique (1997), entre outros, discutem a evolução da paisagem associada aos processos tectônicos do Cenozóico.

O presente estudo, utilizando produtos de sensores remotos, teve como principal objetivo a individualização da diversidade morfológica regional, tais como: diferentes unidades de relevo associadas à planície e a planalto, que abarcam platôs, colinas, terraços, paranás (termo que se refere a um braço de rio que se liga a jusante ao próprio rio), ilhas, lagos, além de outras formas de relevo desenvolvidas pelas ações de fatores endógenos e exógenos, entre outros fatores. $\mathrm{O}$ trabalho se justifica na tentativa de contribuir quanto a análise e caracterização da evolução da paisagem regional e o controle morfoestrutural da área.

\section{Materiais e Métodos}

Para a identificação das unidades geomorfológicas da área de estudo foi adotado os de procedimentos metodológicos do projeto Radambrasil (1976), aprimorado por Ross (2000) e adequado para área, segundo suas peculiaridades. Para confecção dos mapas foram utilizadas as seguintes bases cartográficas, na escala 1:100. 000: Itacoatiara - Folha SA. 21-Y- D4/ MI 582; Itapiranga - Folha SA. 21 - Y-B-IV/MI-0521; Anebá - Folha SA. 21-Y-A-VI/MI- 520 e São José do Amatari - Folha SA. 21- Y-C-III/MI-58.

A interpretação geomorfológica, a qual adotou a delimitação de padrões semelhantes de textura e estrutura das formas de relevo, foi desenvolvida sobre imagens de sensores remotos Landsat 5-TM e Modelo Digital dp Terreno - SRTM, (Shulttle Radar Topography Mission), tratada por meio do softwear Global Mapper $5.0 \mathrm{e}$, posteriormente, exportada no formato Geotiff para o software Arcview GIS 3.3. Foram aplicadas algumas combinações de imagens Landsat 5-TM e SRTM para destacar relevo, drenagem e estruturas. As formas de relevo foram separadas de acordo com as altitudes, definidas em unidades ou zonas homólogas. Essas zonas foram definidas com base em sua gênese e classificadas em formas de acumulação e denudação. 


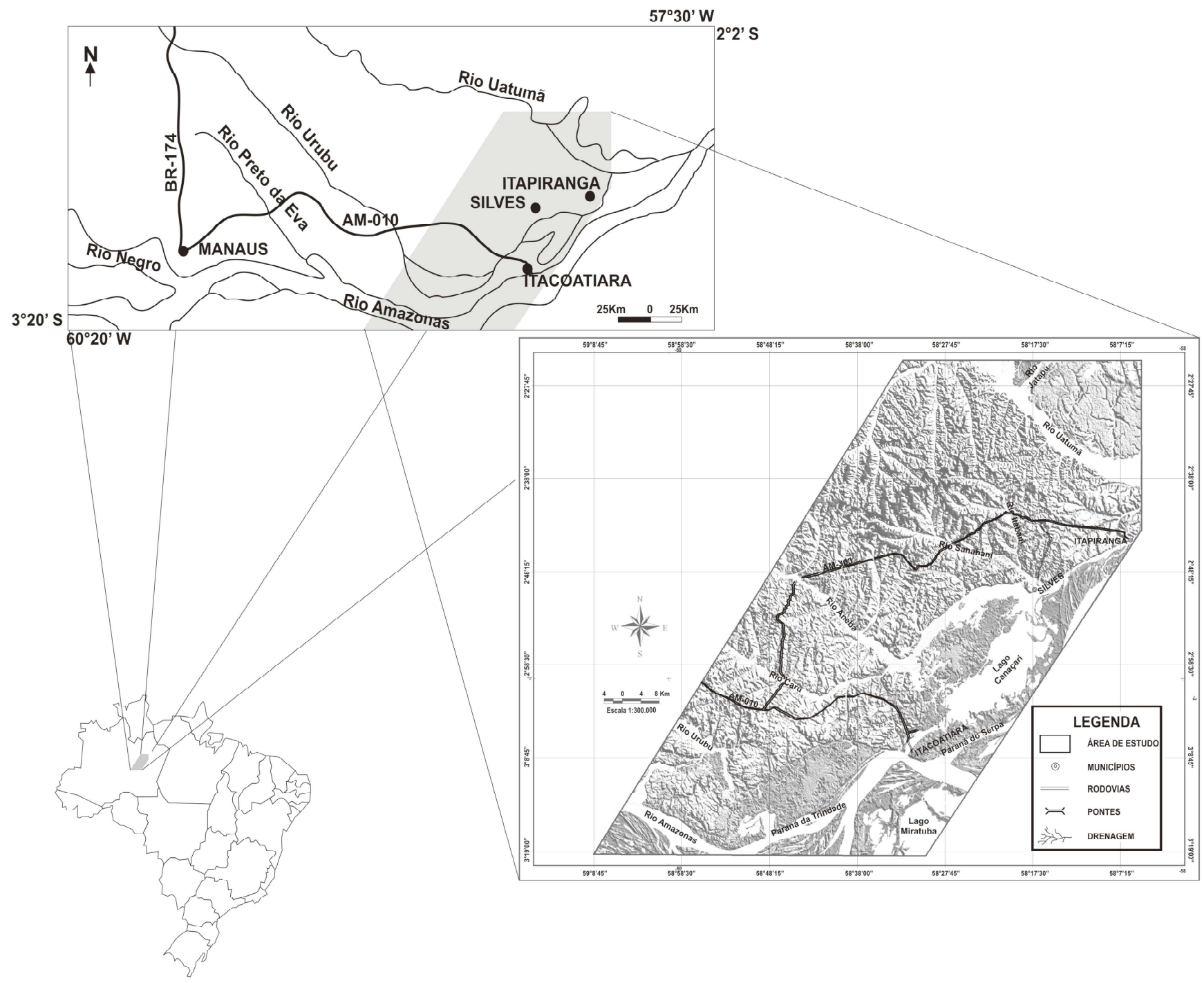

Figura 1 - Localização da área de estudo.

As formas denudacionais, tais como platôs e colinas, foram definidas e separadas em função de seu perfil (forma e altitude) as quais receberam uma codificação: (Dc) para as colinas de topos convexos, (Dptc) platôs de topos convexos, (Dpta) platôs de topos aplainados, (Dptac) platôs de topos aplainados e conservados.

As formas de acumulação como as planícies e terraços fluviais foram identificadas por meio das características hidrodinâmicas, tais como a presença de áreas alagadas e áreas inundáveis, cuja codificação (Apf) para as planícies fluviais, (Apfa) planície fluvial alagada, (Apfi) planície fluvial inundável, e (Atf) para os terraços fluviais.

A análise do padrão de drenagem obedeceu aos pressupostos metodológicos de Howard (1967) e as propriedades de drenagem: tropia, sinuosidade, angularidade e assimetria, bem como densidade de drenagem, em Soares e Fiori (1976). Já os elementos estruturais (lineamentos fotointerpretados) foram agrupados, em função de suas magnitudes, de forma decrescente em $1^{\mathrm{a}}, 2^{\mathrm{a}}$ e $3^{\mathrm{a}}$ ordens. As direções preferenciais desses elementos foram agrupadas e representadas sob a forma de rosetas, aplicando o software Arcview GIS 3.3.

\section{Contexto Geológico Local}

A maior parte da área estudada compreende as rochas sedimentares da Formação Alter do Chão (Cretáceo Superior), e estreita faixa de sedimentos da Formação Novo Remanso (Terciário), na porção SW da área. Essa última formação foi definida por Rozo (2004), 
ao perceber que, na margem esquerda do Rio Amazonas nas proximidades das comunidades de Novo Remanso (AM) e São José do Amatari (AM), ocorrem sedimentos discordantes sobre a Formação Alter do Chão.

Litologicamente, essa formação é constituída por camadas de arenitos ferruginosos grossos e areias com granulometria que varia de média a fina, e apresenta estratificação cruzada tabular. Já a Formação Alter do Chão se forma por siltitos, arenitos médios de coloração avermelhada a amarelada com traços de raízes, apresentando estratificação cruzada e acanalada. No entanto, a Formação Alter do Chão e Novo Remanso apresentam o quartzo, a caulinita e os óxi-hidróxidos de ferro (hematita e ghoethita) como seus principais constituintes mineralógicos.

\section{Análise Morfoescultural}

As unidades morfoesculturais tem sua gênese associada ao relevo de degradação e relevo de acumulação. O relevo de degradação está representado por platôs de topos convexos (Dptc), topos aplainados (Dpta), topos aplainados e conservados (Dptac), que apresentam entre 60 a 150 metros de altitudes, e relevo colinoso (Dc) definido por interflúvios abaixo da cota de 90 metros. Esses relevos normalmente são fortemente dissecados, ravinados, sob a influência dos rios Uatumã, Anebá, Caru, Urubu, Itabani e Sanabani, e seus tributários.

O relevo de acumulação compreende formas que se situam em meio à planície fluvial amazônica, que apresentam altitudes entre 20 a 60 metros. As formas mais representativas da planície são: paranás, lagos, ilhas, furos, igarapés e os terraços fluviais. Os terraços (Atf) são constituídos por sedimentos holocênicos antigos e recentes, e estão posicionados a NE e a SW da área. Os terraços a NE se apresentam com até $11 \mathrm{Km}$ de extensão por $8 \mathrm{Km}$ de largura e com altitudes entre 20 a 40 metros. Apresentam vales em forma de $\mathrm{V}$ com até $5.6 \mathrm{Km}$ de extensão por $300 \mathrm{~m}$ de largura, e vales em forma de $\mathrm{U}$ com $8.9 \mathrm{Km}$ de extensão por $400 \mathrm{~m}$ de largura. Já os terraços posicionados a SW, apresentam-se sob forma alongada com até $7 \mathrm{Km}$ de extensão por $2.5 \mathrm{Km}$ de largura e em altitudes cerca de 40 a 60 metros. Os vales desses terraços são fechados em forma de $\mathrm{V}$, medindo até $3 \mathrm{Km}$ de extensão por 1 $\mathrm{Km}$ de largura.
Os paranás, a exemplo o da Trindade, posicionado a SSW com $23 \mathrm{Km}$ de extensão por $4 \mathrm{Km}$ de largura e, o Paraná do Serpa localizado a SSE, com até de $20 \mathrm{Km}$ de extensão por $2 \mathrm{Km}$ de largura. Os lagos são, também, frequentes na planície de inundação, a exemplo o do Canaçari, com forma circular posicionado a SE com cerca de $29 \mathrm{Km}$ de extensão por $13 \mathrm{Km}$ de largura. $\mathrm{Na}$ porção Sul encontra-se o lago Miranduba, com $18 \mathrm{Km}$ de extensão por $5 \mathrm{Km}$ de largura, e o lago da Celsa posicionado a SSE, com até $7 \mathrm{Km}$ de extensão por 6 $\mathrm{Km}$ de largura.

As formas de relevo na área correspondente as planícies fluviais estão sob influência direta da força hidrodinâmica dos rios Amazonas e Uatumã. Na área de estudo, no conjunto da bacia hidrográfica fluvial, o rio Amazonas é o canal principal que percorre duas direções preferenciais. Primeiramente, ao adentrar a área de estudo sob condições litológicas e estruturais - sentido NW-SE, e ao atingir proximidades da comunidade de São José do Amatari e foz do rio Madeira, direciona-se para SW-NE e, nos limites do município de Itacoatiara inflecta novamente pra NW-SE. Os principais afluentes do rio Amazonas na margem direita são os rios: Uatumã, Anebá, Caru e Urubu, que se apresentam sob forte paralelismo, percorrem também direções preferenciais NW-SE e SW-NE. A figura 2 evidencia a interpretação das feições morfoesculturais da área elaborada com base na interpretação dos alinhamentos de drenagens.

Outra característica importante no sistema de drenagem é a assimetria fraca, tropia bidirecional, densidade alta e anomalias, tais como: encurvamento em arco do Igarapé Maquarazinho e dos rios Itabani e Sanabani na porção central da área, bem como a forte retilinaridade do rio Caru, a SW da área.

\section{Caracterização Morfoestrutural}

A partir dos lineamentos de drenagens observa-se, também, os aspectos de assimetria, tropia, sinuosidade, angularidade e anomalias, tais como: vale encaixado na unidade $\mathrm{E}$ da área e encurvamentos em forma de arco na drenagem, que podem ser atribuídos como possíveis movimentos neotectônicos. Na (Figura 3) apresenta-se o estereograma referente aos dados estruturais fotointerpretativos da área estudada, onde se nota que as principais direções de lineamento estão no sentido NW-SE e SW-NE. 
Análise Geomorfológica da Região entre os Municípios de Itacoatiara, Silves e Itapiranga, Nordeste do Estado

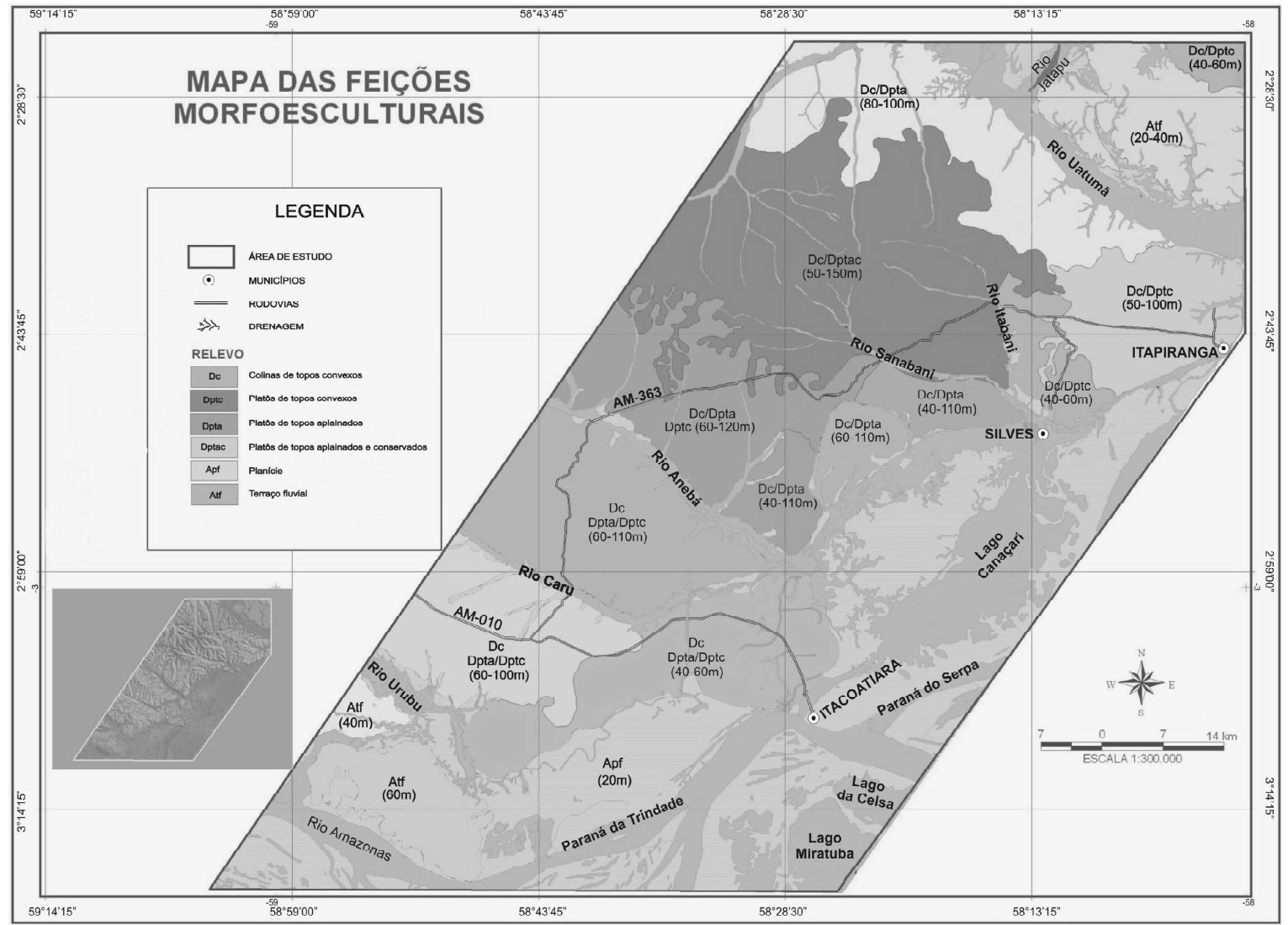

Figura 2 - Mapa das feições morfoesculturais da área. Elaborado com base na imagem do Modelo Digital do Terreno (MDT - SRTM) localizado na zona 21 referente ao ano 2000. Fonte USGS-USA.

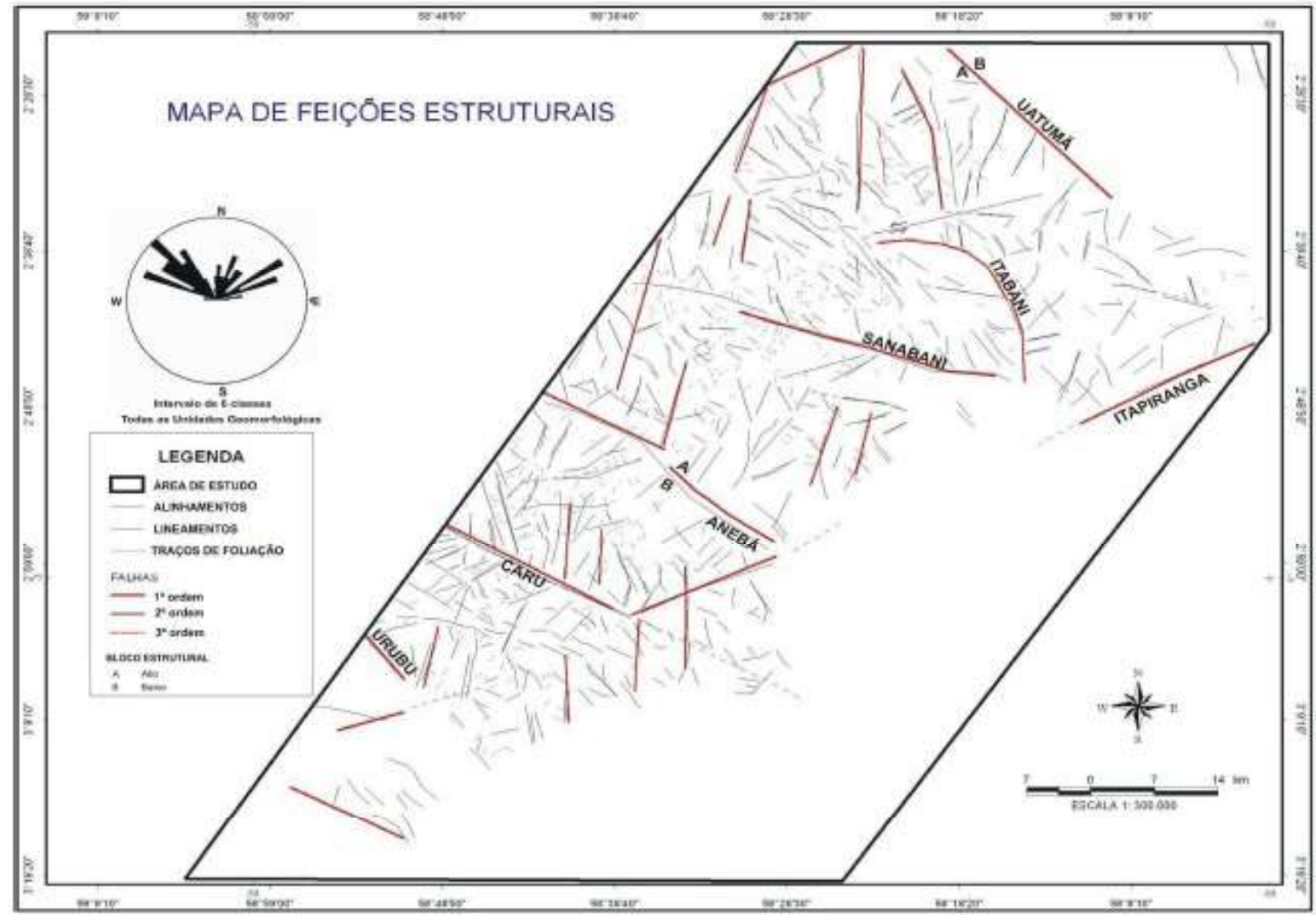

Figura 3 - Mapa de feições estruturais. Elaborado com base no MDT/SRTM, localizado na zona 21 referente ao ano 2000. 
Em uma análise morfoestrutural simples é possível observar que a área de estudo está delimitada por dois lineamentos estruturais principais, nas direções NW-SE e SW-NE de $1^{\text {a }}$ ordem. A porção norte limita-se pelo segmento estrutural NW-SE, o qual controla a drenagem ao longo do rio Uatumã, enquanto que a porção sul é limitada por meio da conjunção entre os lineamentos estruturais NW-SE e SW-NE, os quais controlam os rios Urubu e Amazonas, respectivamente.

No setor centro-norte da área, aqui denominado de bloco morfoestrutural Itapiranga, ocorrem platôs de topos aplainados e conservados (Dptac) e colinas (Dc), com altitudes em torno de 150 e 50 metros, respectivamente. Esse bloco mostra-se limitado ao norte pelo lineamento NW-SE (controlador do rio Uatumã), a leste pelo lineamento SW-NE (controlador do rio Amazonas) e ao sul pelo lineamento NWW-SEE (controlador do rio Sanabani). No interior desse bloco predominam os lineamentos de $2^{\mathrm{a}}$ ordem, ou seja, orientados na direção N-S e NNE-SSW, cujo padrão de drenagem é do tipo dendrítico.

O setor central, aqui denominado de bloco morfoestrutural Silves, mostra-se limitado por meio da articulação dos lineamentos NWW-SEE, SW-NE e NW-SE. Nesse bloco é possível, ainda, individualizar dois subsetores chamados de norte e sul, os quais estão separados pelo lineamento NW-SE (controlador do rio Anebá). No subsetor norte, predominam platôs de topos aplainados e conservados (Dptac), com altitudes da ordem de 150 metros e estruturados por lineamentos N-S e NNE-SSW. Em direção ao subsetor sul, os (Dptac) são substituídos por platôs de topos convexos (Dptc) e de topos aplainados (Dpta), com a altitude baixando para a ordem de 110 metros, e mantendo o predomínio de lineamentos N-S e NNESSW.

O setor sul, denominado de bloco morfoestrutural Itacoatiara, se apresenta limitado pelos lineamentos NW-SE e N-SSW. Nesse bloco, também, é possível individualizar dois subsetores, denominados de norte e sul, os quais se separam pelos lineamentos NW-SE (controladores dos rios Urubu, Caru e Amazonas). No subsetor norte ocorrem platôs de topos aplainados (Dpta), de topos convexos (Dptc) e sistema de colinas (Dc) com altitudes de 100 e 60 metros com predominância do lineamento NW-SE (controladores dos rios Caru e Urubu) de $3^{\mathrm{a}}$ ordem, e pelos lineamentos de $2^{\mathrm{a}}$ ordem com direções N-SSW, que controlam cristas do relevo. No subsetor sul predominam platôs de topos aplainados (Dpta), de topos convexos (Dptc), sistemas de colinas (Dc) com altitudes rebaixadas (60 a $40 \mathrm{~m}$ ) e terraços fluviais (Atf) com até 60 metros de altitudes, rios de $1^{\mathrm{a}}$ e $2^{\mathrm{a}}$ ordem e padrão de drenagem do tipo subdendrítico, controlados pelos lineamentos de $1^{\mathrm{a}}$ ordem (NWSE).

Os lineamentos de direção NW-SE e SW-NE exercem fortes influências estruturais na área de estudo, controlando essencialmente a configuração da rede de drenagem e sistema de relevo. Tal controle estrutural há muito tempo tem sido discutido por diversos pesquisadores, entre os quais (STERNBERG, 1950; FRANZINELLI; PIUCI, 1988; FRANZINELLI; IGREJA, 1990; COSTA et al. 1991, 1992, 1994 e 1996; FERNANDES FILHO et al. 1995; HASUY, 1996; IGREJA e CATIQUE, 1997; FRANZINELLE et al. 2002).

Segundo Miranda et al. (1994 apud Costa, 2002), na região do Rio Uatumã, $89 \%$ das falhas normais desenvolvidas sobre os sedimentos da Formação Alter do Chão estão orientadas, preferencialmente, segundo direções NNE-SSW e NE-SW, sugerindo a atuação de esforços distensivos nas direções WNWESE e NW-SE. O restante das estruturas observadas (11\%), correspondem a falhas reversas com orientação preferencial NNE-SSW e NE-SW sugerindo a atuação de esforços compressivos WNW-ESSE e NW-SE. Miranda et al. (1994 apud Costa, 2002) destacaram, ainda, a presença de descontinuidades com orientação NW-SE no embasamento, as quais coincidem com o interflúvio Uatumã-Anebá e representam, possivelmente, altos e baixos estruturais do substrato cristalino.

Segundo Costa et al. (1994, 1995 e 1996), na região compreendida entre as cidades de Manaus e Juruti (PA) existem dois conjuntos de estruturas decorrentes de movimentos tectônicos durante o Terciário Superior e o Quaternário. As estruturas mais antigas (Figura 4) correspondem às falhas inversas 
orientadas, segundo a direção NE-SW (controladoras do sistema de colinas) desenvolvidas sobre os sedimentos da Formação Alter do Chão, podendo estar associada a dobras, falhas transcorrentes e normais, definindo domínios transpressivo, direcional e distensivo, respectivamente. Por outro lado, as estruturas do Quaternário são representadas pelos seguintes elementos: um segmento distensivo, situado entre as cidades de Manacapuru (AM) e Itacoatiara, um segmento transcorrente na região da ilha de Tupinambarana, e duas junções tríplices denominadas Baixo Tapajós e Marajó - Mexiana. O segmento distensivo Manacapuru e Itacoatiara são caracterizados por falhas normais orientadas na direção NW-SE, que controlam o traçado geral dos rios Preto da Eva, Urubu, Uatumã e o baixo curso do Rio Negro, além de impor desnivelamento de até 30 metros no perfil laterítico desenvolvido no PliocenoPleistoceno.

Quanto a um breve enquadramento da geotectônica, a região nordeste do Estado do Amazonas experimentou, nos últimos 20 milhões de anos, uma maior dinâmica da chamada neotectônica, marcada pela geração de falhas que rebaixaram, rotacionaram e/ou soerguiram blocos rochosos (FRANZINELE; PIUCI, 1988; FRANZINELLE e IGREJA, 1990; COSTA e HASUÍ, 1991; COSTA, 1996, CUNHA, 1992; COSTA et al. 1992 e 1994; HASUÍ 1990 e 1996, BORGES et al. 1995, CUNHA et. al. 1994, FRANZINELLI et al. 2002). Outro importante agente no modelado da geomorfologia na região foi o clima, sobretudo durante os períodos Neógeno e Quaternário (GINGRAS et al. 2002), quando a região foi submetida a oscilações climáticas responsáveis pela parcial remoção da cobertura de floresta e a formação de extensos platôs lateríticos (COSTA, 1991).

Segundo Costa et al. (1992) e Costa et al. (1994), as estruturas neotectônicas na região Amazônica estão marcadas por dois episódios de movimentação, sendo um no Terciário Superior (Mioceno Plioceno) e outro no Quaternário. Na região entre as cidades de Manaus e Itacoatiara (AM), objeto desse estudo, destacamse estruturas do Terciário Superior, marcadas pelo desenvolvimento de vários feixes de falhas inversas na direção NE-SW e inclinados preferencialmente para SE, porém, no interflúvio do rio Preto da Eva/Urubu, ocorrem duplexes e sistemas imbricados afetando os sedimentos da Formação Alter do Chão.

A ação de um componente transcorrente na região da cidade de Itacoatiara, cuja cinemática é interpretada como dextral, também tem sido discutida por Igreja e Catique (1997), como responsável pelo controle estrutural na foz do rio Madeira e no desenvolvimento de lagos, ilhas e paranás naquela região. Tal tectônica transcorrente dextral é também estendida para a foz do rio Negro, à qual favoreceria a captura de drenagens, formação de cachoeiras e ilhas (IGREJA et al. 1999; FRANZINELLI et al. 1999).

A análise geométrica dos elementos estruturais fotointerpretativos auxiliada pelas restritas observações em campo da ação de falhas normais em arranjo lístrico, permitiu elaborar um arranjo morfoestrutural representado por sistema de prismas escalonados para área de estudo (Figura 4B). Tal concepção distribui os blocos estruturais Itapiranga, Silves e Itacoatiara, conforme seus padrões de relevo e drenagem, como áreas mais rebaixadas, tais como as planícies de inundação controlados, principalmente, pela articulação de falhamentos normais NW-SE e NE-SW. É provável que tais blocos ou prismas não tenham simplesmente deslizados um em relação ao outro, mas, que tenham sido submetidos a um componente rotacional no sentido horário, especialmente entre os blocos morfoestruturais Itapiranga e Silves, os quais ainda necessitam de melhor investigação.

Em geral, podemos considerar que os blocos morfoestruturais individualizados na área de estudo estão escalonados com as áreas mais rebaixadas localizadas na porção sul, e as mais elevadas na porção centro-norte. Tal escalonamento permite projetar os blocos com ângulos de mergulhos em torno de $25^{\circ}$ na direção SW e, ao longo da conjunção entre os blocos ou prismas morfoestruturais, estão desenvolvidas as drenagens dos rios Urubu, Caru, Anebá, Sanabani e Uatumã, com fluxos d'água de NW para SE, refletindo a provável rotação dos blocos no sentido horário (Figura 4B). 

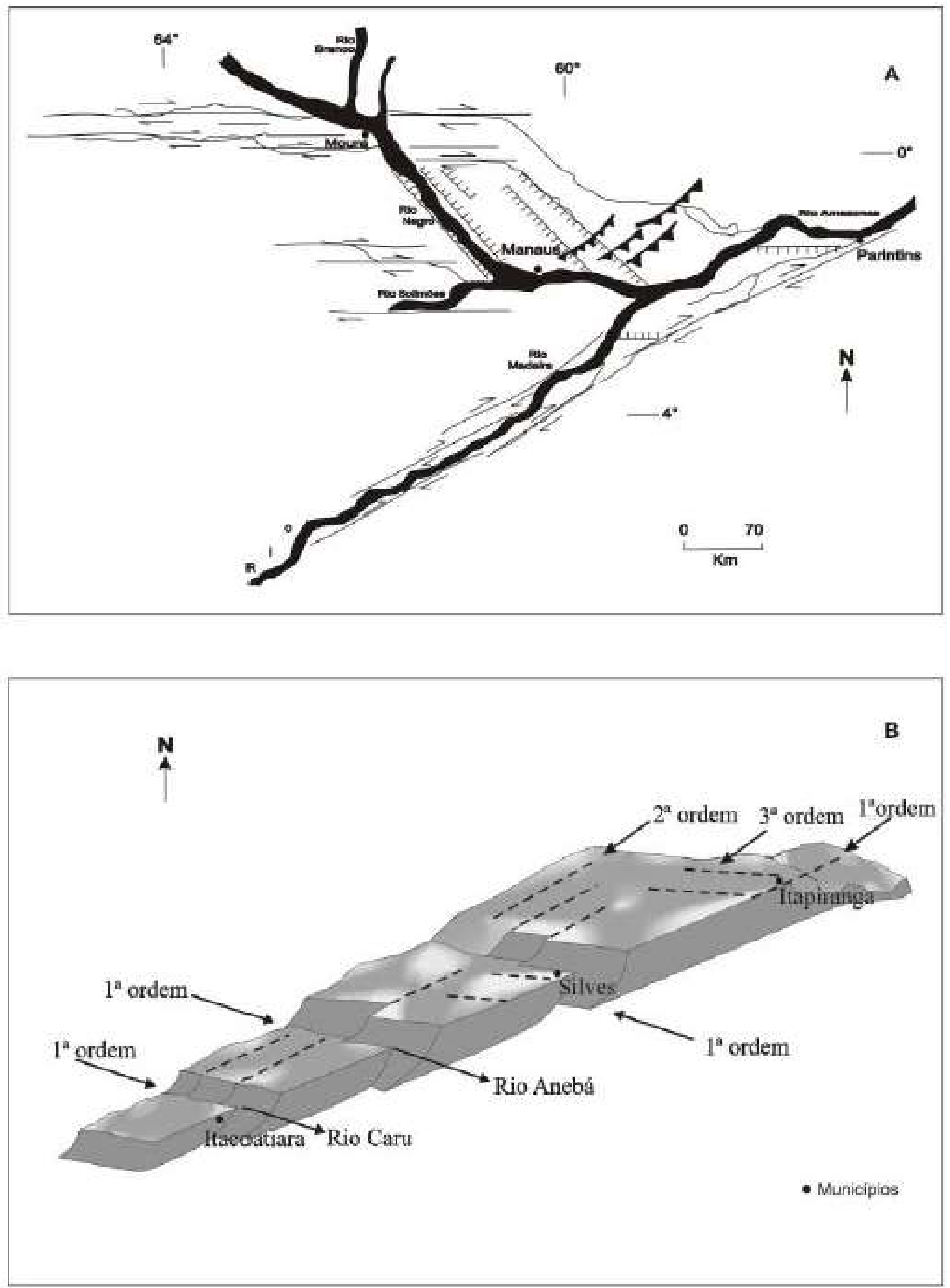

Figura 4 - A) Maiores estruturas neotectônicas da região leste do estado do Amazonas. Fonte: Costa et al. (1996). B) Bloco diagrama em arranjo morfoestrutural indicando um sistema de prismas, formado por 4 blocos observados em diferentes compartimentos estruturais. 


\section{Considerações Finais}

As pesquisas geomorfológicas auxiliadas pelas bases cartográficas, acervo bibliográfico, trabalho de campo e produtos de sensoriamento remoto, permitiram descrever a influência das unidades geológicas, o comportamento do sistema de drenagem, as morfoesculturas e o controle morfoestrutural da área de estudo.

A rede de drenagem da área pesquisada mostra-se controlada por segmentos estruturais nas direções NW-SE e SW-NE e NNE. Tais segmentos estruturais controlam os rios Amazonas, Uatumã, Urubu, Caru e Anebá, enquanto que os segmentos estruturais NNE-SSW e N-S controlam as cristas do relevo, e os de direções NWW-SEE, SWW-NEE e W-E controlam o rio Sanabani e, principalmente, rios e igarapés de $1^{\mathrm{a}} \mathrm{e}$ $2^{\mathrm{a}}$ ordens.

A evolução Cenozóica da área, notabiliza-se pelos processos neotectônicos, cujas evidências são observadas no controle estrutural com direções preferenciais NW-SE, SW- NE, NNE-SSW e W-E, que controlam principais drenagens e alinhamento de relevo (cristas) e as formas anômalas na rede de drenagem. Tal arranjo estrutural está configurado sob a forma de prismas escalonados, limitados por falhas em arranjo lístrico, mergulhando cerca de $25^{\circ}$ para SW. É provável que tais prismas tenham sido submetidos a um componente rotacional horário, o qual ainda necessita de maiores investigações. Essa configuração permite explicar a distribuição das formas de relevo e drenagem, além da compartimentação dos perfis lateríticos na área em estudo, colocando os prismas ou blocos mais rebaixados na porção sul e os mais elevados na porção centro-norte da área.

\section{Agradecimentos}

Os autores agradecem ao Instituto de Geociências da Universidade Federal do Amazonas (DEGEO) pelo apoio concedido durante a pesquisa e a FAPEAM (Fundação de Amparo a Pesquisa do Amazonas) pelo auxílio financeiro.

\section{Referências Bibliográficas}

COSTA, J. B. S; HASUÍ, Y. O quadro geral da evolução tectônica da Amazônia. In: SIMPÓSIO NACIONAL DE ESTUDOS TECTÔNICOS, 3, Rio Claro, Boletim... Rio Claro: UNESP e
SBG, p.142-145. 1991.

COSTA, J. B. S; HASUÍ, Y; BEMERGUY, R. L; BORGES, M. S; COSTA, A. R; TRAVASSO, J. A. M; IGREJA, H. L.S. Aspectos Fundamentais de neotectônica da Amazônia Brasileira. In: INT. SIMP. QUATERNÁRIO DAAMAZÔNIA. Anais... Recursos e Contribuição Científica. Manaus, ABEQUA. 1992. p. 103-106.

COSTA, J. B. S; HASUI, Y; BORGES, M. S; BEMERGUY, R. L; SAADI, A; COSTA Jr., P. S., Arcabouço tectônico mesocenozóico da região da calha do Amazonas. In: SIMPÓSIO DE GEOLOGIA DAAMAZÔNIA, 4. Belém. Anais... Belém, SBG. p. 47-50. 1994.

COSTA, J. B. S; BEMERGUY, R. L; HASUI, Y; BORGES, M. S; FERREIRA Jr, C. R. P; BEZERRA, P.E.L; COSTA, M.L; FERNANDES, J.M.G. Neotectônica da região Amazônica: aspectos estruturais, tectônicos, geomorfológicos e estratigráficos. Geonomos. IV (2) p. 23-24. 1996.

COSTA, J. B. S.; HASUI, Y.; BORGES, M. S.; BEMERGUY, R. L. Arcabouço tectônico meso-cenozóico da região da calha do Rio Amazonas. Geociências. São Paulo, 14 (2): p. 77-103. 1995. COSTA, J. B. S. A Neotectônica na Amazônia. In: SIMPÓSIO DE GEOLOGIA DA AMAZÔNIA, 5, Belém. Boletim de Resumos Expandidos... Belém: SBG, p. 35-38. 1996.

COSTA, J. B. S; BEMERGUY, R. L; HASUI Y, BORGES, M. da $\mathrm{S}$. Tectonicsn and paleogeograph along Amazon river. Jour. South Amer. Earth Sci., 14: p. 335-347. 2001.

COSTA, A. R. A. Tectônica Cenozóica e Movimentação Salífera na Bacia do Amazonas e suas relações com a Geodinâmica das Placas da América do Sul, Caribe, Cocos e Nazca. 2002. 237f. (Dissertação de Mestrado), Belém.

FERNANDES FILHO, L. A; COSTA, J. B. S; COSTA, M. L. Bacia de Manaus: uma estrutura pull-apart do Quaternário. In: SIMPÓSIO NACIONAL DE ESTUDOS TECTÔNICOS, 5.5. Gramado, 1995. Boletim de Resumos Expandidos... Porto Alegre: SBG/RS e CPGQ/UFRGS, p. 419-420. 1995.

FRANZINELLI, E.; PIUCI, J. Evidências de neotectonismo na Bacia Amazônica. In: Congresso Latino-americano de Geologia. 7, Anais... p. 80-90. 1988.

FRANZINELLI, E; IGREJA, H. L. S. Utilização do Sensoriamento Remoto na investigação na área do baixo Rio Negro e Grande Manaus. In: SIMPÓSIO BRASILEIRO DE SENSORIAMENTO REMOTO, 6. Anais... 3. p. 641-648. 1990. Modern Sedimentation. In: The Lower Negro River, Amazonas State, Brazil. Geomorphology (44); p. 259271. 2002. 
GINGRAS, M. K.; RASANEN, M.; RANZI, A. The significance of bioturbated inclined heterolthic stratification in the Sourthern part of the Miocene Solimões Formation, rio Acre, Amazônia, Brazil. An International Journal of SEPM (Society for Sedimentary Geology). v. 17. nº 6., 2002. p. 591-601.

HASUÍ, Y. Evolução geológica da Amazônia. In: SIMP. GEOL. AMAZ. 5. Belém. 1996. Boletim de resumos expandidos... Belém, SBG; p. 31-34. 1996.

HOWARD, A. D. Drainage analysis in geologic interpretation: summation. Bulletin American Association of Petroleum Geologists, Tulsa, v.5, n.11. p. 2246-2259. 1967.

IGREJA, H. L.S.; CATIQUE, J. Análise Neotectônica do Lineamento de Itacoatiara Centro-Leste do Estado do Amazonas. In: VI SIMP. NAC. DE ESTUDOS. Tectônicos. Pirenópolis-GO. SBG/JG-UNB, p. 131-133. 1997.

IGREJA, H. L.S; FRANZINELLI, E; REPOLHO, T. Neotectonic Influence on Fluvial Capture in the Amazon Basin. State of Amazon, Brazil. Science Reports of Tohoku. Univesity, 7 th Series (Geography). Vol. 49, n. 2. p. 197-206. 1999.

IRIONDO, M.; SUGUIO, K. Neotectonics of the Amazon plain. Bulletin of the INQUANetectonic Commission, 4: p. 2-78. 1981.
NASCIMENTO, D. A. do MAURO, C. A. de GARGIA, M. das G. L. Geomorfologia. In: BRASIL. DEPARTAMENTO NACIONAL DA PRODUÇÃO MINERAL. Projeto RADAMBRASIL Folha SA-21-Santarém. Rio de Janeiro, 1976. p. 522 (Levantamento de Recursos Naturais, 10). 1976.

RADAMBRASIL. Folha S. A-21 - Santarém: geologia, geomorfologia, pedologia, vegetação e uso da terra. Rio de Janeiro: DNPM, 1976 (Levantamento de Recursos Naturais, 10). p. 220

ROSS, J.L.S. Geomorfologia: ambiente e planejamento. 5 ed. São Paulo: Contexto, p. 85. 2000.

ROZO, J. M. G. Evolução deposicional do canal fluvial do rio Amazonas, no setor entre a ilha do Careiro e a foz do rio madeira. 2004. 93 f. Dissertação (Mestrado em Geociências). Departamento de Geologia, Universidade Federal do Amazonas, Manaus.

SOARES, P. C; FIORI, A. P. Lógica e Sistemática na análise e interpretação de fotografias aéreas em geologia. 16 (32): p. 17.1976.

STERNBERG, H. O'Reilly. Vales tectônicos na planície Amazônica. R. Bras. Geogr. Rio de janeiro. 12 (4): p. 3-26, out/dez. 1950. 